\title{
Cellulolytic Activities of Strains of the Genus Cellulomonas
}

\author{
DONALD W. THAYER, ${ }^{*}$ STEVEN V. LOWTHER, $†$ AND JOHN G. PHILLIPS \\ Eastern Regional Research Center, Agricultural Research Service, United States Department of Agriculture, Philadelphia, \\ Pennsylvania 19118
}

\begin{abstract}
The effects of $\mathrm{pH}$, temperature, the presence or absence of glucose and cellobiose, and culture medium on cellulase synthesis or activity or both by 12 strains of Cellulomonas were compared. The liquefaction of carboxymethyl cellulose (CMC) gels by eight of the strains was examined. The optimum temperature for hydrolysis of $\mathrm{CMC}$ during growth was $40^{\circ} \mathrm{C}$, and the optimum $\mathrm{pH}$ was 7 to 7.5 . The eight strains broke into two distinct groups with a fourfold difference in rates of $\mathrm{CMC}$ or filter paper hydrolysis during growth. The presence of either glucose or cellobiose in the culture medium stimulated growth but repressed either the synthesis or the activity of CMC and filter paper cellulases. This effect is the opposite of that reported previously for Bacillus CMC cellulase. The greatest rate of filter paper hydrolysis occurred in a synthetic medium. The cell-free carboxymethylcellulase of Cellulomonas flavigena ATCC $482^{\mathrm{T}}$ was partially purified by molecular exclusion chromatography on Bio-Gel P-100 and Sephadex G-75. The partially purified enzyme had a molecular weight of 40,000 and optimum activity at $\mathrm{pH} 7.0$. Cellobiose was a competitive inhibitor of the enzyme activity. The results obtained with the partially purified enzyme indicated that the results obtained by using CMC gels were valid.
\end{abstract}

Members of the genus Cellulomonas are coryneform bacteria whose most recognized feature is the ability to attack cellulose. Much of the recent interest in the members of this genus has arisen because of their ability to produce singlecell protein from cellulosic substrates $(6,7)$.

The taxonomy of this group has been the subject of some debate. In Bergey's Manual of Determinative Bacteriology, 7th ed., 10 species were recognized; however, only a single species was recognized in Bergey's Manual, 8th ed. (10). The serological properties of cell wall antigens of six strains of the genus Cellulomonas were compared by Braden and Thayer (3). The percentage of cross-reactions varied from 43 to $93 \%$. In no instance did a heterologous reaction equal the homologous reaction, and as a result these authors questioned the reduction of the genus to a single species. In 1979, Stackebrandt and Kandler (17) proposed seven species based on deoxyribonucleic acid (DNA) reassociation studies. The DNA homology values within the genus ranged from 20 to $100 \%$.

Stewart and Leatherwood (18) reported the isolation of mutants of Cellulomonas fimi which had derepressed synthesis of cellulase. The wild-type organism had no measurable cellulase activity when it was grown in the presence of either $1 \%$ glucose or cellobiose. Cellobiose but not glucose inhibited enzyme activity of the wild-type organism toward both cellulose and carboxymethyl cellulose (CMC). Cellobiose, cellulose, and sophorose at low concentrations induced cellulase synthesis in both the wild-type and mutant organisms. Using an unidentified strain of Cellulomonas, Beguin and Eisen (2) reported partial purification of the extracellular endo-1,4- $\beta$-glucanase. Endo-1,4- $\beta$-glucanases attack regions of low crystallinity in the cellulose fiber, creating free chain ends. The cellobiose in turn is usually hydrolyzed by the action of a $\beta$-glucosidase or cellobiose phosphorylase. Stoppok et al. (19) reported that the extracellular endoglucanase activity of Cellulomonas uda was inhibited by cellobiose but not by glucose. The optimum $\mathrm{pH}$ for this enzyme was $\mathrm{pH}$

\footnotetext{
* Corresponding author.

$\dagger$ Deceased.
}

7.0. $\beta$-Glucosidase activity was reported to be inhibited noncompetitively by glucose.

Although investigators have studied the ability of individual species to produce cellulase, no one has reported on a systematic comparison of the cellulases of several strains under identical conditions. The purpose of this study was to compare the cellulolytic activities of 12 strains of the genus Cellulomonas and to test the validity of the simple gel hydrolysis technique used in some of the studies by partial purification and characterization of an extracellular cellulase produced by Cellulomonas flavigena.

\section{MATERIALS AND METHODS}

Bacterial strains. The following strains of bacteria were used in this study and were obtained from the American Type Culture Collection, Rockville, Md.: Cellulomonas biazotea ATCC $486^{\mathrm{T}}(\mathrm{T}=$ type strain), Cellulomonas cartae ATCC $21681^{\mathrm{T}}$, Cellulomonas cellasea ATCC 487, C. fimi ATCC $484^{\mathrm{T}}, C$. fimi ATCC 8183, C. fimi ATCC 15724, Cellulomonas flavigena ATCC $482^{\mathrm{T}}$, Cellulomonas gelida ATCC $488^{\mathrm{T}}$, Cellulomonas sp. strain ATCC 21399 , Cellulomonas sp. strain JHHY35, "Cellulomonas subalbus" ATCC 489 , and $C$. uda ATCC $491^{\mathrm{T}}$. The Cellulomonas sp. strain designated JHHY35 was isolated from an enrichment culture by Harris (J. H. Harris, Ph.D. thesis, Texas Tech University, Lubbock, 1977). Both the enrichment culture and the defined mixed culture of which Cellulomonas sp. strain JHHY 35 is a member have been described previously (2224).

Media and growth conditions. Stock cultures were routinely maintained on Trypticase soy agar (BD Microbiology Systems, Cockeysville, Md.) incubated at $35^{\circ} \mathrm{C}$ and stored at $4^{\circ} \mathrm{C}$. Inocula were grown in Trypticase soy broth (BBL Microbiology Systems, Cockeysville, Md.) for $48 \mathrm{~h}$ at $35^{\circ} \mathrm{C}$.

CMC depolymerization. The method used for determining the rate of $C M C$ depolymerization was based on an observation of Reese et al. (14) that fungi liquify CMC gels from the top of the medium to the bottom. In this study the rates of depolymerization were measured by determining the liquefaction of gels containing type 7HF sodium CMC (Hercules 
Inc., Wilmington, Del.), which has a degree of substitution of 0.7 and a degree of polymerization of 3,200 (21). The medium had the following composition (per liter): $\mathrm{NaCl}, 5.0$ $\mathrm{g}$; CMC, $25 \mathrm{~g}$; Phytone peptone (BBL), $10.0 \mathrm{~g}$; and tap water. The $\mathrm{pH}$ was adjusted to 7.0 , and the medium was dispensed into test tubes ( 16 by $150 \mathrm{~mm}$ ) and sterilized for 15 min at $121^{\circ} \mathrm{C}$. In some experiments the gel was buffered with $0.1 \mathrm{M}$ potassium phosphate to varying $\mathrm{pH}$ values. The media were inoculated with $0.05 \mathrm{ml}$ of culture per tube. Depolymerization proceeded from the surface toward the bottom of the gel with zero-order kinetics, reducing the gel to water-like viscosity. Gel depolymerization was measured at 2-day intervals for 16 to 20 days. The depolymerization rates of CMC-containing media were always compared within the same experiment at different $\mathrm{pH}$ values or temperatures. The rates of depolymerization were calculated by a least-squares analysis of all measurements in which less than $100 \%$ of the gel was liquefied.

Filter paper disintegration. The ability to attack native cellulose was determined by suspending strips $(0.4$ by $13 \mathrm{~cm})$ of Whatman no. 1 filter paper in tubes containing cultures of varying compositions and observing the time required for the filter paper strips to weaken to the breaking point (16). The first medium contained $0.5 \%$ peptone (Difco Laboratories, Detroit, Mich.), $0.5 \% \mathrm{NaCl}$, and distilled water. The second medium contained the ingredients of the first medium plus $0.1 \%$ yeast extract (Difco). A third medium contained $0.5 \%$ peptone (Difco), $0.5 \% \mathrm{NaCl}, 0.1 \%$ yeast extract (Difco), and $0.5 \% \beta$-D-(+)-cellobiose (Sigma Chemical Co., St. Louis, Mo.). The fourth medium contained $0.5 \%$ peptone (Difco), $0.1 \%$ yeast extract (Difco), $0.5 \% \mathrm{NaCl}, 0.2 \%\left(\mathrm{NH}_{4}\right)_{2} \mathrm{SO}_{4}$, $0.1 \% \mathrm{KH}_{2} \mathrm{PO}_{4}, 0.1 \% \mathrm{~K}_{2} \mathrm{HPO}_{4}, 0.005 \% \mathrm{MgSO}_{4}$, and $0.005 \%$ $\mathrm{CaCl}_{2}$. The fifth medium was the fourth medium plus $0.5 \% \beta-$ $\mathrm{D}-(+)$-cellobiose (Sigma). The media were adjusted to $\mathrm{pH}$ 7.0.

CMCase purification. Carboxymethylcellulase (CMCase) was isolated from the cell-free supernatants of stationary phase cultures. C. flavigena ATCC $482^{\mathrm{T}}$ was grown in medium containing $0.5 \%$ type C8758 CMC (Sigma), $0.2 \%$ yeast extract, $0.5 \% \mathrm{~K}_{2} \mathrm{HPO}_{4}$, and $0.1 \%\left(\mathrm{NH}_{4}\right)_{2} \mathrm{SO}_{4}(\mathrm{pH} 7.1)$. Cultures were grown in $600 \mathrm{ml}$ of medium in 2,800-ml baffled Fernbach flasks and were incubated at $35^{\circ} \mathrm{C}$ while they were agitated at $200 \mathrm{rpm}$ on a gyratory shaker. The culture supernatants were lyophilized and dissolved in $40 \mathrm{ml}$ of distilled water, producing a 30 -fold concentration. A $40-\mathrm{ml}$ portion of the concentrate was eluted from a Bio-Gel P-100 (Bio-Rad Laboratories, Richmond, Calif.) column ( 5.0 by 72 $\mathrm{cm}$ ) with $0.05 \mathrm{M}$, phosphate buffer $(\mathrm{pH} 7.0)$. The flow rate was $33 \mathrm{ml} / \mathrm{h}$ at a hydrostatic pressure of $22 \mathrm{~cm}$ and $4^{\circ} \mathrm{C}$. All fractions with CMCase activity were pooled and lyophilized. The dried material was suspended in $10 \mathrm{ml}$ of distilled water and applied to a Sephadex G-75 (Pharmacia, Uppsala, Sweden) column $(2.5$ by $50 \mathrm{~cm})$. The flow rate was $7.5 \mathrm{ml} / \mathrm{h}$ at $4^{\circ} \mathrm{C}$ and a hydrostatic pressure of $20 \mathrm{~cm}$. This column was calibrated for molecular weight determination by using the following standards from Pharmacia: aldolase, ovalbumin, chymotrypsinogen $\mathrm{A}$, and ribonuclease $\mathrm{A}$.

Determination of enzymatic activities. The rate of saccharification of CMC was determined by the method of Miller et al. (13). A 1-ml portion of $0.5 \% \mathrm{CMC}$ substrate was added to $1.0 \mathrm{ml}$ of enzyme solution. This assay mixture was incubated for $30 \mathrm{~min}$ at $35^{\circ} \mathrm{C}$ and agitated at $200 \mathrm{rpm}$ in a water bath shaker. The reaction was stopped by adding $3.0 \mathrm{ml}$ of dinitrosalicyclic acid reagent. After development of color by heating at $100^{\circ} \mathrm{C}$ for $15 \mathrm{~min}$, the absorbance at $640 \mathrm{~nm}$ was determined to measure the release of reducing sugar. One unit of saccharification activity catalyzed the formation of 1 $\mu \mathrm{mol}$ of product per min under the conditions of the assay.

The effect of the enzymatic activity on the viscosity of $\mathrm{CMC}$ was determined at $35.0 \pm 0.05^{\circ} \mathrm{C}$ by comparing the flow rate in an Ostwald Viscometer with that of water.

Sodium CMC type 7LF (Hercules) was used as the substrate for the assays described above. The CMC solutions were prepared by the method of Hulme (9) after dissolving the powder in $0.05 \mathrm{M}$ potassium phosphate buffer ( $\mathrm{pH} 7.0)$. Sodium azide $(0.2 \%, \mathrm{wt} / \mathrm{vol})$ was added as a preservative.

Avicel PH101 cellulose (FMC Corp., Newark, Del.) was used as the substrate for the determination of the ability of the cellulase to hydrolyze crystalline cellulose. Avicel $(5.0 \mathrm{~g})$ was suspended in $100 \mathrm{ml}$ of $0.05 \mathrm{M}$ phosphate buffer ( $\mathrm{pH}$ 7.0 ), and the release of reducing sugar was measured as described above with dinitrosalicylic acid. para-Nitrophenyl- $\beta$-glucosidase was assayed by the method of Yamane et al. (25), and protein was assayed by the method of Lowry et al. (11).

The inhibition of CMCase activity by sugars was determined viscometrically. The sugars were added at concentrations of $0.5 \%$ to a solution of $0.5 \%$ type $7 \mathrm{LF} \mathrm{CMC} \mathrm{in} 0.05 \mathrm{M}$ potassium phosphate buffer ( $\mathrm{pH} 7.0)$.

The reaction rate constant for the saccharification of $\mathrm{CMC}$ was determined by using several substrate concentrations. CMC solutions were prepared at concentrations of $0.2,0.4$, $0.6,1.2$, and $2.0 \%$ (wt/vol). A $1-\mathrm{ml}$ portion of substrate was added to $1.0 \mathrm{ml}$ of enzyme solution. The mixtures were incubated for $10,20,40,60$, and $80 \mathrm{~min}$. The reactions were stopped by adding $3.0 \mathrm{ml}$ of dinitrosalicylic acid reagent (13). The rate constants were determined graphically by using the following first-order rate equation of Ghose and Das (5): $K t$ $=\ln \left(H_{\mathrm{co}} / H_{\text {co }}-H_{\mathrm{c}}\right)$, where $K$ is the rate constant, $t$ is the incubation time, $H_{\text {co }}$ is the initial cellulose concentration, and $H_{\mathrm{c}}$ is the amount of cellulose saccharified (in terms of milligrams of glucose).

The sugars produced by the action of the purified enzyme on CMC were identified by thin-layer chromatography (1). A $1-\mathrm{ml}$ portion of enzyme was added to $1.0 \mathrm{ml}$ of $0.5 \% \mathrm{CMC}$, and the preparation was incubated for $48 \mathrm{~h}$ at $35^{\circ} \mathrm{C}$. Then 2 $\mu \mathrm{g}$ of each reference sugar was applied to the plate coated with Silica Gel G (Merck) ( $0.1 \mathrm{M}$ sodium bisulfite; 110 to $120^{\circ} \mathrm{C} ; 1 \mathrm{~h} ; 0.25-\mathrm{mm}$ layer). Cellobiose, lactose, sucrose, maltose, fructose, and glucose were used as standards. The solvent system used contained ethyl acetate, methanol, glacial acetic acid, and water (12:3:3:2, vol/vol). The chromatograms were developed by using a benzidine reagent (12).

\section{RESULTS}

Figure 1 shows the results of an experiment in which $C$. uda ATCC $491^{\mathrm{T}}, C$. gelida ATCC $488^{\mathrm{T}}, C$. cellasea ATCC 487, "C. subalbus" ATCC 489, Cellulomonas sp. strain ATCC $21399, C$. biazotea ATCC $486^{\mathrm{T}}, C$. flavigena ATCC $482^{\mathrm{T}}$, and $C$. fimi ATCC $484^{\mathrm{T}}$ were compared at different $\mathrm{pH}$ values. The CMC depolymerase activity broke into two broad classifications (either relatively high activity or relatively low activity). C. biazotea, C. fimi, and C. flavigena had the lowest depolymerase activities. A statistical analysis indicated that the results obtained with $C$. biazotea, $C$. fimi, and $C$. flavigena were significantly $(P<0.001)$ different from those obtained with the other five species in the peptoneCMC gels without added carbohydrate. The Scheffe test (15) revealed that the mean of the activity for Cellulomonas sp. strain ATCC 21399 was significantly different from that of $C$. 


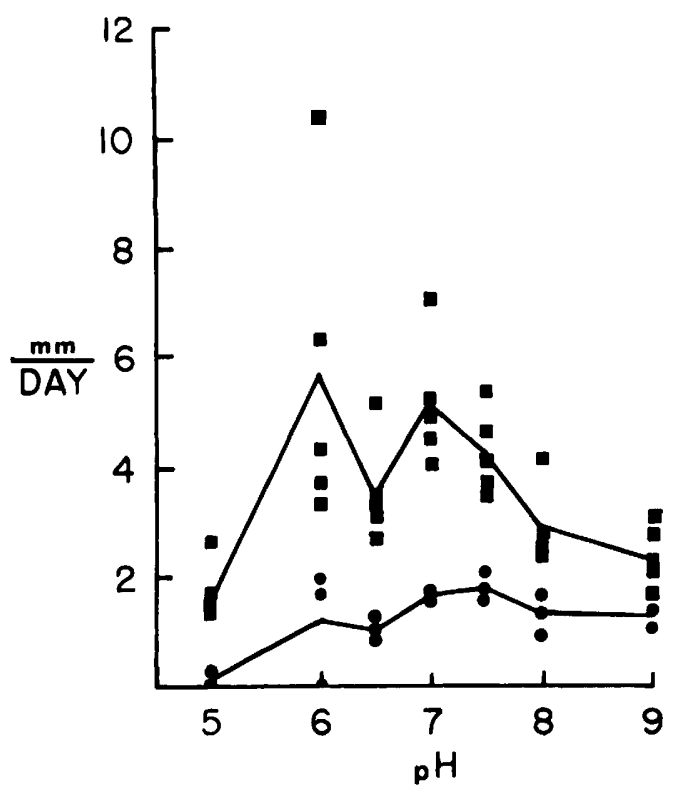

FIG. 1. Comparison of rates of hydrolysis of $2.5 \% \mathrm{CMC}$ in peptone- $\mathrm{NaCl}$ broth at different $\mathrm{pH}$ values by eight strains of the genus Cellulomonas. C. biazotea ATCC $486^{\mathrm{T}}$, C. fimi ATCC $484^{\mathrm{T}}$, and $C$. flavigena ATCC $482^{\mathrm{T}}$ had the least activity $(\bullet)$, and the average value for these three species is represented by the bottom curve. $C$. cellasea ATCC $487, C$. gelida ATCC $488^{\mathrm{T}}$, "C. subalbus" ATCC 489, C. uda ATCC $491^{\mathrm{T}}$, and Cellulomonas sp. strain ATCC 21399 are represented by the upper curve, which is the average value for all five species. $\mathbf{a}$, Individual results.

uda ATCC $491^{\mathrm{T}}$, C. fimi ATCC $484^{\mathrm{T}}$, C. biazotea ATCC $486^{\mathrm{T}}$, or $C$. flavigena ATCC $482^{\mathrm{T}}$. The mean activity of $C$. flavigena ATCC $482^{\mathrm{T}}$ was significantly different from the mean activity of Cellulomonas sp. strain ATCC 21399 and the mean activity of " $C$. subalbus" ATCC 489 . There was evidence of a significant $(P<0.01)$ quadratic relationship between $\mathrm{pH}$ and enzymatic activity. Peaks in enzymatic activity were observed at $\mathrm{pH} 6$ and 7 for all species, with minimum values occurring at $\mathrm{pH} 5$ and 9 .

When the activities of the organisms against CMC were measured at different temperatures (Fig. 2), the optimum was $40^{\circ} \mathrm{C}$ for the depolymerization of CMC for all cultures. The optimum temperature for growth was $30^{\circ} \mathrm{C}$. Again, $C$. biazotea, C. fimi, and C. flavigena had the lowest depolymerase activities and were significantly $(P<0.001)$ different from the remaining five species.

The CMC depolymerase activities of the eight strains listed in the legend to Fig. 1 were compared with and without glucose or cellobiose added to the media. The averages of the results for C. cellasea ATCC 487, C. gelida ATCC $488^{\mathrm{T}}$, Cellulomonas sp. strain ATCC 21399, "C. subalbus" ATCC 489, and C. uda ATCC $491^{\mathrm{T}}$ are shown in Fig. 3 as examples. Similar results were obtained with all eight species. The greatest activity occurred in the absence of added sugar; the least activity occurred in the presence of added cellobiose, and the effect of added glucose was intermediate. The slope of the line decreased when cellobiose but not glucose was added to the medium, which suggests that cellobiose affects a different reaction than does glucose, although both compounds markedly decreased the rate of CMC gel hydrolysis.

The results of studies of filter paper breakage by 12 strains of Cellulomonas are summarized in Table 1. Filter paper breakage was enhanced by the addition of yeast extract to the peptone- $\mathrm{NaCl}$ broth and was enhanced further by the

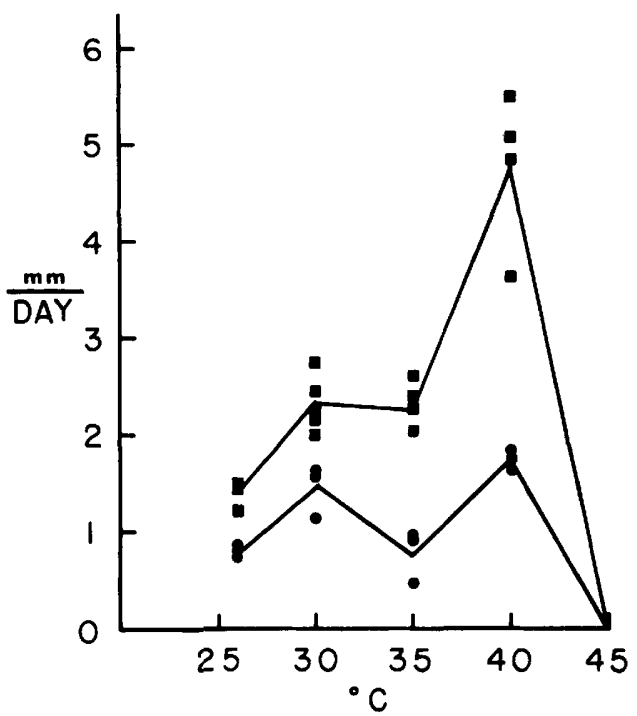

FIG. 2. Comparison of the rates of hydrolysis of $2.5 \% \mathrm{CMC}$ in peptone- $\mathrm{NaCl}$ broth at different temperatures by eight strains of the genus Cellulomonas. For activities and species identification see the legend to Fig. 1.

addition of a mineral salts mixture. These results may have been due to increased growth; Cellulomonas species are known to require biotin and thiamine. The addition of cellobiose to the media inhibited filter paper strip breakage for at least 26 days. The culture designated $C$. fimi ATCC 8183 by its depositor failed to break the filter paper.

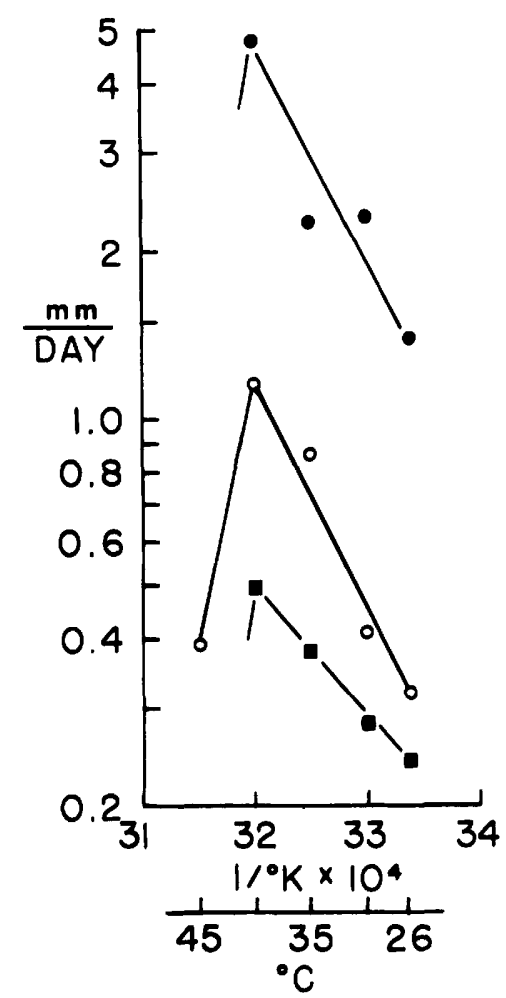

FIG. 3. Arrhenius plot of the average rate of hydrolysis of a $2.5 \%$ CMC gel by $C$. cellasea ATCC $487, C$. gelida ATCC $488^{\mathrm{T}}$, " $C$. subalbus" ATCC 489, C. uda ATCC $491^{\mathrm{T}}$, and Cellulomonas sp. strain ATCC 21399 in 2.5\% CMC without added glucose or cellobiose $(\mathbf{O})$ or in the presence of added $0.5 \%$ glucose $(O)$ or $0.5 \%$ cellobiose (a). 
TABLE 1. Time required for the breakage of filter paper strips by Cellulomonas strains

\begin{tabular}{|c|c|c|c|c|c|}
\hline \multirow{2}{*}{ Strain } & \multicolumn{5}{|c|}{ Filter paper breakage in the following media: ${ }^{a}$} \\
\hline & $P$ & PY & PYC & PYM & PYMC \\
\hline C. biazotea ATCC $486^{\mathrm{T}}$ &,,$+++(14)$ &,,$+++(4)$ &,,$+++(26)$ &,,$+++(3)$ &,,--- \\
\hline C. cartae ATCC $21681^{\mathrm{T}}$ &,,$+++(4)$ &,,$+++(4)$ &,,--- &,,$+++(3)$ &,,,--- \\
\hline C. cellasea ATCC 487 &,,$+++(26)$ &,,$+++(7)$ &,,--- &,,$+++(3)$ &,,--- \\
\hline C. fimi ATCC $484^{\mathrm{T}}$ &,,$+++(26)$ &,,$+++(10)$ &,,--- &,,$+++(3)$ &,,$++-(26)$ \\
\hline C. fimi ATCC 8183 &,,--- &,,--- &,,--- &,,--- &,,--- \\
\hline C. fimi ATCC 15724 &,,$+++(14)$ &,,$+++(4)$ &,,$++-(26)$ &,,$+++(4)$ &,,--- \\
\hline C. flavigena ATCC $482^{\mathrm{T}}$ &,,$+++(14)$ &,,$+++(10)$ &,,--- &,,$+++(3)$ &,,--- \\
\hline Cellulomonas sp strain ATCC 21399 &,,$+++(10)$ &,,$+++(4)$ &,,--- &,,$+++(3)$ &,,--- \\
\hline C. gelida ATCC $488^{\mathrm{T}}$ &,,$+++(26)$ &,,$+++(7)$ &,,--- &,,$+++(3)$ &,,--- \\
\hline "C. subalbus" ATCC 489 &,,$+++(14)$ &,,$+++(4)$ &,,--- &,,$+++(3)$ &,,--- \\
\hline C. uda ATCC $491^{\mathrm{T}}$ &,,$+++(14)$ &,,$+++(4)$ &,,--- &,,$+++(3)$ &,,--- \\
\hline Cellulomonas sp strain JHHY35 &,,$+++(10)$ &,,$+++(4)$ &,,$+++(26)$ &,,$+++(3)$ &,,--- \\
\hline
\end{tabular}

${ }^{a} \mathrm{P}$, peptone- $\mathrm{NaCl}$ medium; $\mathrm{PY}$, peptone-NaCl-yeast extract medium; $\mathrm{PYC}$, peptone-NaCl-yeast extract-cellobiose medium; $\mathrm{PYM}$, peptone-NaCl-mineral salts medium; PYMC, peptone-NaCl-yeast extract-mineral salts-collobiose medium.

${ }^{b}$ Results obtained in three replicate tests. The numbers in parentheses indicate the number of days of incubation required to obtain a positive test. The study was terminated after 26 days, and all remaining tubes in which the filter paper strips had not broken were recorded as negative.

Because the assays described above for the effects of temperature, $\mathrm{pH}$, or added sugars on the rates of CMC gel liquefaction could not completely differentiate between growth-related events and direct effects on enzymatic activity, the extracellular CMCase of $C$. flavigena ATCC $482^{\mathrm{T}}$ was partially purified and characterized to test the validity of the conclusions concerning the effects of $\mathrm{pH}$, and glucose, and cellobiose on the activity of a purified enzyme. Preliminary experiments in which CMCase activity was assayed by viscometric measurements established that both $C$. biazotea and $C$. flavigena ATCC $482^{\mathrm{T}}$ produced CMCase activities associated both with washed cells and cell-free culture liquor. Most (80\%) of the CMCase activity was associated with the cell-free culture liquor. All 12 strains studied produced cell-free CMCase when they were grown in glucose-free Trypticase soy broth in the absence of cellulose, and the activity of the enzyme(s) was completely inhibited by the presence of cellobiose. Both $C$. biazotea and $C$. flavigena cultures produced the greatest activity during late $\log$ phase growth. C. flavigena ATCC $482^{\mathrm{T}}$ was selected for further study because it is the type strain of the type species of the genus Cellulomonas and previous workers have not reported purification of its cellulase(s). Purification efforts were limited in this study to the cell-free enzyme(s) and were designed to determine whether the CMC gel hydrolysis system produced an accurate assessment of the CMCase activities of the cultures.

The relationship between the growth of $C$. flavigena and extracellular CMCase is shown in Fig. 4. The CMCase was released into the culture medium during the late log phase. No appreciable growth was observed in a duplicate culture medium lacking $\mathrm{CMC}$, which indicates that $C$. flavigena was able to use CMC as a carbon and energy source. The level of CMCase increased to a maximum during stationary phase. Therefore, the cell-free liquor from stationary cultures was selected as the substrate for purification of the enzyme(s). The purification of the cell-free CMCase is presented in Table 2. A $1-\mathrm{ml}$ portion of this purified preparation was concentrated 10 -fold by lyophilization and rechromatographed on a calibrated Sephadex G-75 column. All CMCase activity and protein were found in fractions $(4.5 \mathrm{ml}) 28$ through 30 . The elution volume for the purified CMCase was compared with the elution volumes for standards; this resulted in a molecular weight estimate of 40,000 .

Neither the original culture supernatant nor the purified CMCase had $p$-nitrophenyl- $\beta$-glucosidase activity. Howev- er, both the supernatant and the purified enzyme were active against crystalline cellulose (Avicel). The specific activity of the enzyme (Avicelase) against crystalline cellulose was increased approximately 10 -fold during purification, from 0.02 to $0.21 \mathrm{mg}$ of reducing sugar per $\mathrm{mg}$ of protein in $2 \mathrm{~h}$. It should be noted that the CMC depolymerase CMC saccharification specific activity was increased approximately 40 fold during the purification procedure (Table 2).

The CMCase activity of the purified enzyme was maximal at $\mathrm{pH} 7.0$ (Fig. 5). All subsequent experiments were conducted at $\mathrm{pH} 7.0$.

Cellobiose (or possibly maltose) was the only detectable product of the action of the purified enzyme(s) on CMC. Cellobiose was, however, the only sugar which had any inhibitory effect on CMCase activity. The effects of increasing cellobiose concentrations on CMCase activity are shown in Fig. 6. The percentage of inhibition ranged from none at $1.1 \mathrm{mM}$ cellobiose to $95 \%$ at $22.5 \mathrm{mM}$ cellobiose.

A reciprocal plot of CMCase activity versus CMC concentration is shown in Fig. 7. The approximate $K_{m}$ for type 7LF $\mathrm{CMC}$ was $7.5 \mathrm{mg} / \mathrm{ml}$, as determined from this graph. Figure 7 also illustrates the effect of cellobiose on both the $K_{m}$ and the

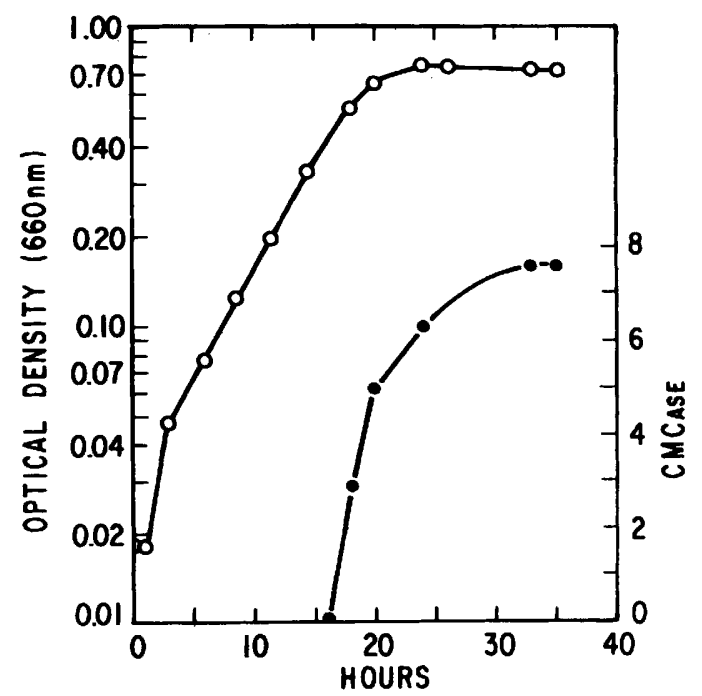

FIG. 4. C. Alavigena ATCC $482^{\mathrm{T}}$ growth (optical density at 660 $\mathrm{nm})(O)$ and extracellular CMCase activity (viscometric units per milliliter) (๑). 
TABLE 2. Purification of CMCase

\begin{tabular}{|c|c|c|c|c|c|c|c|}
\hline Fraction & $\begin{array}{l}\text { Total vol } \\
\quad(\mathrm{ml})\end{array}$ & $\begin{array}{l}\text { CMCase } \\
\text { activity } \\
(\mathrm{U})^{a}\end{array}$ & Total units & $\begin{array}{l}\text { Protein } \\
\text { concn } \\
(\mathrm{mg} / \mathrm{ml})\end{array}$ & $\begin{array}{c}\text { Specific CMC ac- } \\
\text { tivity }(\mathrm{U} / \mathrm{mg} \text { of } \\
\text { protein) }\end{array}$ & $\begin{array}{c}\% \\
\text { Recovery }\end{array}$ & $\begin{array}{l}\text { Specific sac- } \\
\text { charification } \\
\text { activity } \\
\text { ( } \mu \mathrm{mol} / \mathrm{min} \text { per } \\
\text { mg of protein) }\end{array}$ \\
\hline Culture supernatant & 1,200 & 2.4 & $2,880.0$ & 0.74 & & 100.00 & 0.052 \\
\hline First lyophilization & 40 & 66.1 & $2,640.0$ & 14.3 & & 91.7 & \\
\hline $\begin{array}{l}\text { Bio-gel } \\
\text { P-100 }\end{array}$ & 350 & 4.9 & $1,720.0$ & 0.07 & 69.0 & 59.7 & 1.26 \\
\hline Second lyophilization & 10 & 169.2 & $1,692.0$ & 2.34 & 72.3 & 58.8 & \\
\hline $\begin{array}{l}\text { Sephadex } \\
\text { G-75 }\end{array}$ & 52.8 & 8.1 & 430.0 & 0.058 & 139.7 & 14.9 & 2.28 \\
\hline
\end{tabular}

${ }^{a}$ One CMCase unit $=\mathrm{d}\left(n_{\mathrm{sp}}\right) / \mathrm{d} t \times 10^{2}$.

$V_{\max }$ for the enzyme reaction. Cellobiose was added to each CMC solution at a concentration of $9.2 \mathrm{mM}$. The approximate $K_{m}$ increased to $37.8 \mathrm{mg} / \mathrm{ml}$, whereas the $V_{\max }$ remained relatively unchanged. Thus, cellobiose caused inhibition and appeared to be a competitive inhibitor for the saccharification of type 7LF CMC. However, because our data failed to establish the unequivocal purity of a cellulase, the $K_{m}$ values should be viewed with caution.

A Ghose-Das plot is shown in Fig. 8. The $K$ value increased from $2.6 \times 10^{-3} / \mathrm{min}$ to $7.4 \times 10^{-2} / \mathrm{min}$ between 0.6 and $1.2 \% \mathrm{CMC}$. The effects of the degree of substitution, the degree of polymerization, and the molecular weight of the CMC on CMCase activity are presented in Table 3 . The activity of the CMCase was 33-fold greater against type 12M31 CMC than against type 7LF CMC. There was little change in the activities measured with type $12 \mathrm{M} 31 \mathrm{CMC}$ and type $7 \mathrm{HF}$ CMC. Our results did not indicate a clear linkage to either the degree of polymerization or the molecular weight of the substrate, but did clearly indicate that the apparent activity was directly related to the viscosity of the solution.

\section{DISCUSSION}

The results obtained in this study are dramatically different from those reported by Thayer (20) for the activity of a CMC depolymerase produced by Bacillus cereus RW1. In that case there was an enhancement of activity when either cellobiose or glucose was added to the medium.

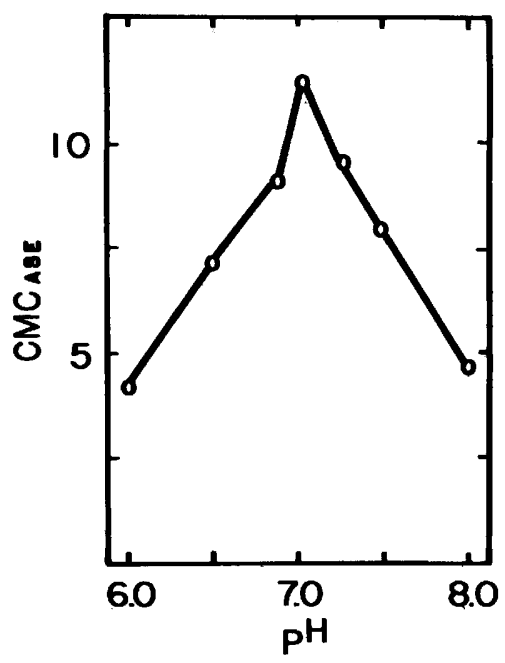

FIG. 5. Effect of $\mathrm{pH}$ on the rate of reduction of CMC viscosity by the purified CMCase of $C$. flavigena ATCC $482^{\mathrm{T}}$.
The results of this study indicate that in general the properties of the cellulases and cellulase synthesis by eight strains of Cellulomonas are very similar. However, the activities against $\mathrm{CMC}$ can be separated into two broad groups.

The extracellular CMCase partially characterized in this study corresponds to an endo- $\beta$-1,4-glucanase (EC 3.2.1.4). The end product is most probably cellobiose, but the chromatographic method which we used cannot clearly differentiate between cellobiose and maltose. The depolymerase activity of this enzyme is much greater than its saccharification activity.

The partially purified extracellular enzyme(s) was active against both $\mathrm{CMC}$ and Avicel. Further studies will be necessary to determine whether there is more than one enzyme present in the product of molecular exclusion chromatography described above. Similar results have been reported by other workers. Chang and Thayer (4) purified a periplasmic cellulase from Cytophaga that was active against both CMC and Avicel. Yamane et al. (25) reported that the three cellulases which they purified from Pseudomonas fluorescens were active against CMC, swollen cellulose, and Avicel. Thus, this bacterial cellulase system does not appear to follow the $\mathrm{C}_{1}-\mathrm{C}_{\mathrm{X}}$ concept described by Reese et al. for fungal systems (14).

Cellobiose was the only carbohydrate of those tested which was a competitive inhibitor of CMCase activity of the purified extracellular activity of $C$. flavigena ATCC $482^{\mathrm{T}}$. Since a similar inhibition of activity against filter paper strips and $\mathrm{CMC}$ was observed in the growing cultures, this inhibi-

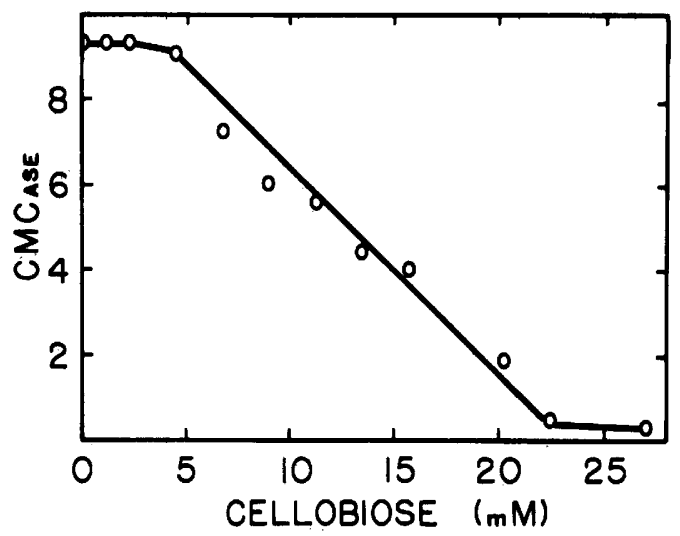

FIG. 6. Effect of cellobiose on the activity of the purified CMCase of $C$. flavigena ATCC $482^{\mathrm{T}}$ (measured viscometrically). The experimental results obtained at the 12 concentrations tested are indicated $(O)$. 


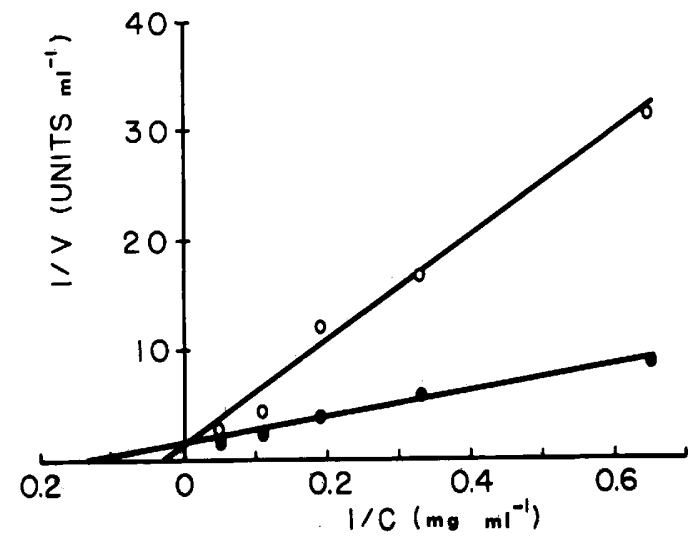

FIG. 7. Reciprocal plot of $C$. flavigena ATCC $482^{\mathrm{T}}$ activity versus CMC concentration. Symbols: 9 , CMCase activity without added cellobiose; $O$, CMCase activity in the presence of $9.2 \mathrm{mM}$ added cellobiose.

tion may also apply to Avicelase activity and definitely applies to the CMCase activities of all species and strains of Cellulomonas tested. The absence of CMCase activity in growing Cellulomonas cultures when $0.5 \%$ glucose was added to the culture medium was not due to inhibition of the enzyme. A high glucose concentration may have had an inhibitory effect on $\beta$-glucosidase activity and resulted, in turn, in an accumulation of cellobiose which either inhibited or possibly repressed the synthesis of the CMCase and Avicelase enzyme(s).

Ghose and Das (5) proposed an equation $\left[K t=\ln \left(H_{\mathrm{co}} / H_{\mathrm{co}}\right.\right.$ $\left.-H_{\mathrm{c}}\right)$ ] to determine the reaction order and the rate constant for CMCases. At each concentration of $\mathrm{CMC}$, a straight line was obtained for the CMCase activity of this extracellular $C$. flavigena enzyme. This indicates that this CMCase follows first-order kinetics. A higher rate of saccharification was observed with increasing CMC concentration. Chang and Thayer (4) observed exactly the opposite effect of increased concentrations of the purified CMCase of Cytophaga; the rate of saccharification decreased with increasing $\mathrm{CMC}$ concentration. The sharp increase in reaction rate observed in this study between 0.6 and $1.2 \%$ CMC may provide support for the proposal of Hofsten (8) that cellulase activity is enhanced by a favorable alignment between the enzyme

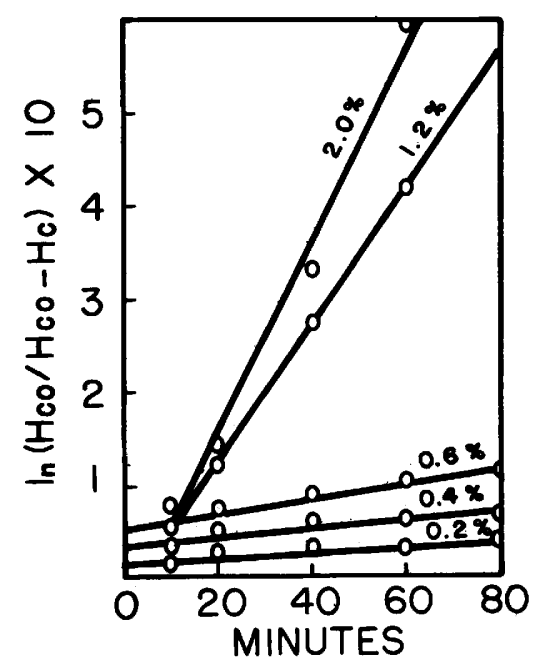

FIG. 8. Ghose-Das plot at different concentrations of CMC.
TABLE 3. Effect of CMC type on CMCase activity

\begin{tabular}{lccrr}
\hline $\begin{array}{l}\text { CMC } \\
\text { type }^{a}\end{array}$ & $\begin{array}{c}\text { Degree of } \\
\text { substitu- } \\
\text { tion }\end{array}$ & $\begin{array}{c}\text { Degree of } \\
\text { polymer- } \\
\text { ization }\end{array}$ & Mol wt & $\begin{array}{r}\text { CMCase } \\
\text { activity } \\
(\mathrm{U} / \mathrm{ml})^{b}\end{array}$ \\
\hline 7LF & $0.65-0.85$ & 400 & 80,000 & 7.0 \\
12M31 & $1.2-1.4$ & 1,100 & 250,000 & 232.2 \\
$7 \mathrm{HF}$ & $0.65-0.85$ & 3,200 & 700,000 & 233.8 \\
\hline
\end{tabular}

${ }^{a}$ All solutions were $0.5 \%$ (wt/vol); all CMCs were obtained from Hercules Inc.

${ }^{b}$ One CMCase unit $=\mathrm{d}\left(n_{\mathrm{sp}}\right) \mathrm{d} t^{-1} \times 10^{2}$.

and its substrate. The CMC in the more concentrated solutions may have undergone a conformational change, making it more susceptible to enzymatic hydrolysis. However, this hypothesis does not explain the results obtained with Cytophaga. The results obtained in this study with type $7 \mathrm{LF}, 7 \mathrm{HF}$, and $12 \mathrm{M} 31 \mathrm{CMCs}$ also support the hypothesis of Hofsten, since the higher viscosities of type 7HF and 12M31 $\mathrm{CMCs}$ tend to make the polymers more ordered in solution and thus provide a more favorable enzyme-substrate association.

With the exception of $C$. fimi ATCC 8183 , all 12 strains of Cellulomonas which we examined were cellulolytic. We recently learned that $C$. fimi ATCC 8183 has been classified as a member of the genus Arthrobacter (F. Fiedler, Ph.D. thesis, University, Munich, Federal Republic of Germany, 1971), supporting the conclusion reached in this study that this strain is physiologically dissimilar from the other strains tested. The cellulolytic activities of all strains were inhibited (or repressed) by the presence of glucose or cellobiose to varying degrees. In this study CMC gel liquefaction rates grouped eight of the Cellulomonas strains tested into two phena. $C$. biazotea ATCC $486^{\mathrm{T}}, C$. fimi ATCC $484^{\mathrm{T}}$, and $C$. flavigena ATCC $482^{\mathrm{T}}$ fell into a phenon with low CMC liquefaction activities. $C$. cellasea ATCC 487, C. gelida ATCC $488^{\mathrm{T}}$, "C. subalbus" ATCC 489, C. uda ATCC $491^{\mathrm{T}}$, and Cellulomonas sp. strain ATCC 21399 had statistically significant greater $\mathrm{CMC}$ liquefaction activities. To determine whether these results might have taxonomic significance, the DNA homologies reported by Stackebrandt and Kandler (17) were compared. Values for all eight strains were not reported, but the level of DNA homology for $C$. biazotea ATCC $486^{\mathrm{T}}$, and $C$. fimi ATCC $484^{\mathrm{T}}$ was $50.5 \%$. C. gelida ATCC $488^{\mathrm{T}}$ and $C$. uda ATCC $491^{\mathrm{T}}$ had a DNA homology level of $44 \%$. The levels of DNA homology between either $C$. gelida ATCC $488^{\mathrm{T}}$ or C. uda ATCC $491^{\mathrm{T}}$ and Cellulomonas sp. strain ATCC 21399 averaged only $25.2 \%$. When C. biazotea ATCC $486^{\mathrm{T}}$ and $C$. fimi ATCC $484^{\mathrm{T}}$ were compared with $C$. gelida ATCC $488^{\mathrm{T}}, C$. uda ATCC $491^{\mathrm{T}}$, and Cellulomonas sp. strain ATCC 21399, the DNA homology levels averaged $29.2 \%$. Thus, there is support on a genetic basis for considering $C$. biazotea ATCC $486^{\mathrm{T}}$ and C. fimi ATCC $484^{\mathrm{T}}$ to be more closely related to each other than to the other strains.

Braden and Thayer (3) compared the serological properties of the cell wall antigens. C. biazotea ATCC $486^{\mathrm{T}}, C$. fimi ATCC $484^{\mathrm{T}}$, and $C$. flavigena ATCC $482^{\mathrm{T}}$ averaged $86 \%$ serological relationship, and their levels of relationship to $C$. gelida ATCC $488^{\mathrm{T}}$, "C . subalbus" ATCC 489, and $C$. uda ATCC $491^{\mathrm{T}}$ averaged $73.1 \%$. Serologically, $C$. biazotea, $C$. fimi, and C. flavigena were more closely related to each other than to the other strains tested. The results obtained both by Stackebrandt and Kandler and by Braden and Thayer support the conclusion reached in this study. 


\section{ACKNOWLEDGMENTS}

A portion of this study was completed at Texas Tech University and was supported by grants from the Dodge Jones Foundation.

\section{LITERATURE CITED}

1. Adachi, S. 1965. Thin-layer chromatography of carbohydrates in the presence of bisulfite. J. Chromatogr. 17:295-299.

2. Beguin, P., and H. Eisen. 1978. Purification and partial characterization of three extracellular cellulases from Cellulomonas sp. Eur. J. Biochem. 87:515-531.

3. Braden, A. R., and D. W. Thayer. 1976. Serological study of Cellulomonas. Int. J. Syst. Bacteriol. 26:123-126.

4. Chang, W. T. H., and D. W. Thayer. 1977. The cellulase system of a Cytophaga species. Can. J. Microbiol. 23:1285-1292.

5. Ghose, T. K., and K. Das. 1971. A simplified kinetic approach to cellulose-cellulase system. Adv. Biochem. Eng. 1:55-76.

6. Han, Y. W., and C. D. Callihan. 1974. Cellulose fermentation: effect of substrate pretreatment on microbial growth. Appl. Microbiol. 27:159-165.

7. Han, Y. W., and V. R. Srinivasan. 1968. Isolation and characterization of a cellulose-utilizing bacterium. Appl. Microbiol. 16:1140-1145.

8. Hofsten, B. V. 1975. Topological effects in enzymatic and microbial degradation of highly ordered polysaccharides, $p$. 281-295. In Symposium on Enzymatic Hydrolysis. Aulanko, Finland.

9. Hulme, M. A. 1971. Viscometric determination of carboxymethylcellulase in standard international units. Arch. Biochem. Biophys. 147:49-54.

10. Keddie, R. M. 1974. Cellulomonas, p. 629-631. In R. E. Buchanan and N. E. Gibbons (ed.), Bergey's manual of determinative bacteriology, 8th ed. The Williams \& Wilkins Co., Baltimore.

11. Lowry, O. H., N. J. Rosebrough, A. L. Farr, and R. J. Randall. 1951. Protein measurement with the Folin phenol reagent. J. Biol. Chem. 193:265-275.

12. Menzies, I. S., and J. W. T. Seakins. 1969. Sugars, p. 310-329. In I. Smith (ed.), Chromatography and electrophoretic techniques, vol. 1. Chromatography, 3rd ed. Interscience Publishers, New York.
13. Miller, G. L., R. Blum, W. E. Glennon, and A. L. Burton. 1960. Measurement of carboxymethylcellulase activity. Anal. Biochem. 2:127-132.

14. Reese, E. T., R. G. H. Siu, and H. S. Levinson. 1950. The biological degradation of soluble cellulose derivatives and its relationship to the mechanism of cellulose hydrolysis. J. Bacteriol. 59:485-497.

15. Scheffe, H. 1953. A method for judging all contrasts in the analysis of variance. Biometrika 40:87-104.

16. Skerman, V. B. D. 1967 . A guide to the identification of the genera of bacteria, 2nd ed. The Williams \& Wilkins Co., Baltimore.

17. Stackebrandt, E., and O. Kandler. 1979. Taxonomy of the genus Cellulomonas, based on phenotypic characters and deoxyribonucleic acid homology, and proposal of seven neotype strains. Int. J. Syst. Bacteriol. 29:273-282.

18. Stewart, B. J., and J. M. Leatherwood. 1976. Derepressed synthesis of cellulase by Cellulomonas. J. Bacteriol. 128:609615.

19. Stoppok, W., P. Rapp, and F. Wagner. 1982. Formation, location, and regulation of endo-1,4- $\beta$-glucanases and $\beta$-glucosidases from Cellulomonas uda. Appl. Environ. Microbiol. 44:44-53.

20. Thayer, D. W. 1978. Carboxymethylcellulase produced by facultative bacteria from the hind-gut of the termite Reticulitermes hesperus. J. Gen. Microbiol. 106:13-18.

21. Thayer, D. W. 1978. Cellulolytic and physiological activities of bacteria during production of single-cell protein from wood. AlChE Symp. Ser. 74:126-135.

22. Thayer, D. W. 1979 . Woody plants, a renewable fermentation substrate, p. 307-318. In J. R. Goodin and D. K. Northington (ed.), Arid land plant resources. International Center for Arid and Semi-Arid Land Studies, Texas Tech University, Lubbock.

23. Thayer, D. W., and C. A. David. 1978. Growth of "seeded" cellulolytic enrichment cultures on mesquite wood. Appl. Environ. Microbiol. 36:291-296.

24. Thayer, D. W., S. P. Yang, and S.-Y. L. Ou. 1978. Single-cell protein from rice hulls. Dev. Ind. Microbiol. 19:385-393.

25. Yamane, K., H. Suzuki, and K. Nisizawa. 1970. Purification and properties of extracellular and cell-bound cellulase components of Pseudomonas fluorescens var. cellulosa. J. Biochem. (Tokyo) 67:19-35. 